\title{
Sensitivity of stratospheric inorganic chlorine to differences in transport
}

\author{
D. W. Waugh ${ }^{1}$, S. E. Strahan ${ }^{2}$, and P. A. Newman ${ }^{3}$ \\ ${ }^{1}$ Department of Earth and Planetary Science, Johns Hopkins University, Baltimore, MD, USA \\ ${ }^{2}$ University of Maryland Baltimore County, Goddard Earth Sciences and Technology Center, Baltimore, MD, USA \\ ${ }^{3}$ NASA Goddard Space Flight Center, Greenbelt, MD, USA
}

Received: 23 May 2007 - Published in Atmos. Chem. Phys. Discuss.: 21 June 2007

Revised: 10 September 2007 - Accepted: 20 September 2007 - Published: 26 September 2007

\begin{abstract}
Correctly modeling stratospheric inorganic chlorine $\left(\mathrm{Cl}_{\mathrm{y}}\right)$ is crucial for modeling the past and future evolution of stratospheric ozone. However, comparisons of the chemistry climate models used in the latest international assessment of stratospheric ozone depletion have shown large differences in the modeled $\mathrm{Cl}_{\mathrm{y}}$, with these differences explaining many of the differences in the simulated evolution of ozone over the next century. Here in, we examine the role of transport in determining the simulated $\mathrm{Cl}_{\mathrm{y}}$ using three simulations from the same off-line chemical transport model that have the same lower tropospheric boundary conditions and the same chemical solver, but differing resolution and/or meteorological fields. These simulations show that transport plays a key role in determining the $\mathrm{Cl}_{\mathrm{y}}$ distribution, and that $\mathrm{Cl}_{\mathrm{y}}$ depends on both the time scales and pathways of transport. The time air spends in the stratosphere (e.g., the mean age) is an important transport factor determining stratospheric $\mathrm{Cl}_{\mathrm{y}}$, but the relationship between mean age and $\mathrm{Cl}_{\mathrm{y}}$ is not simple. Lower stratospheric $\mathrm{Cl}_{\mathrm{y}}$ depends on the fraction of air that has been in the upper stratosphere, and transport differences between models having the same mean age can result in differences in the fraction of organic chlorine converted into $\mathrm{Cl}_{\mathrm{y}}$. Differences in transport pathways result in differences in vertical profiles of CFCs, and comparisons of observed and modeled CFC profiles provide a stringent test of transport pathways in models.
\end{abstract}

\section{Introduction}

The observed changes in ozone over the last two decades, as well as the expected future increases in the next two decades, are primarily the result of changes in the concentration of stratospheric inorganic chlorine $\left(\mathrm{Cl}_{\mathrm{y}}\right)$ and bromine $\left(\mathrm{Br}_{\mathrm{y}}\right)$.

Correspondence to: D. W. Waugh

(waugh@jhu.edu)
Therefore, correctly modeling stratospheric $\mathrm{Cl}_{\mathrm{y}}$ and $\mathrm{Br}_{\mathrm{y}}$ is crucial for modeling past and future stratospheric ozone levels. However, comparisons of the coupled chemistry climate models (CCMs) used in the latest international assessment of stratospheric ozone (Chapter 6 of WMO, 2007) have shown large differences in the modeled $\mathrm{Cl}_{\mathrm{y}}$, both in terms of magnitude and the date that $\mathrm{Cl}_{\mathrm{y}}$ returns to pre-1980 values (Eyring et al., 2006, 2007). Furthermore, these differences appear to explain many of the differences in simulated ozone between the models, e.g. models with a later return of $\mathrm{Cl}_{\mathrm{y}}$ to pre-1980 values generally have later return of ozone to pre-1980 values. Given its importance for modeling ozone and the large differences between models, it is important to understand the causes of the differences in the simulations of $\mathrm{Cl}_{\mathrm{y}}$.

In the above CCM simulations the same time series of organic chlorine species (e.g., chlorofluorocarbons, CFCs) are specified in the lower troposphere and the same or similar chemical reactions are included in the models. This indicates that the differences in $\mathrm{Cl}_{\mathrm{y}}$ are not due to differences in source gases or stratospheric chemistry but are most likely due to differences in transport.

Here we explore this issue further by examining $\mathrm{Cl}_{\mathrm{y}}$ from three simulations from the same off-line chemical transport model (CTM). The simulations use the same lower tropospheric concentration boundary conditions and the same chemical solver, but differing resolution and/or meteorological fields. As the boundary conditions and chemistry are exactly the same any differences in $\mathrm{Cl}_{\mathrm{y}}$ are due to differences in the transport.

The model and simulations are described in the next section. In Sect. 3 we compare the $\mathrm{Cl}_{\mathrm{y}}$ and mean age $\Gamma$ from the CTM simulations, and Sect. 4 we compare the simulated $\mathrm{Cl}_{\mathrm{y}}$ to estimates using the formulation used by Newman et al. (2006) to calculate EESC. These comparisons show that transport plays a key role in determining the distribution of $\mathrm{Cl}_{\mathrm{y}}$, and that $\mathrm{Cl}_{\mathrm{y}}$ depends on both the time scales and pathways of transport.

Published by Copernicus Publications on behalf of the European Geosciences Union. 
(a) Cly GCM-HIGH

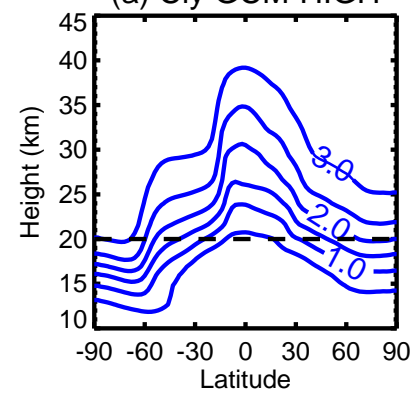

(d) Mean Age GCM-HIGH

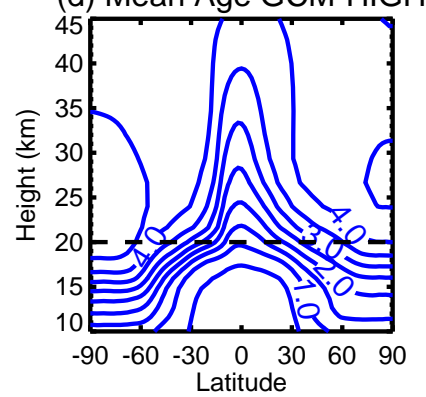

(b) Cly GCM-LOW

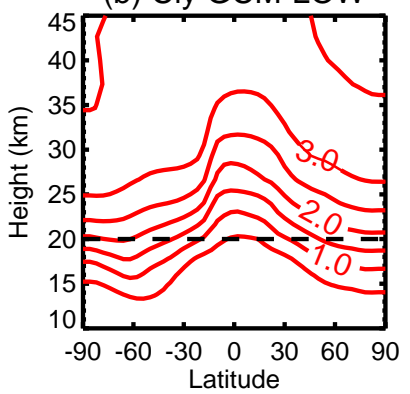

(e) Mean Age GCM-LOW

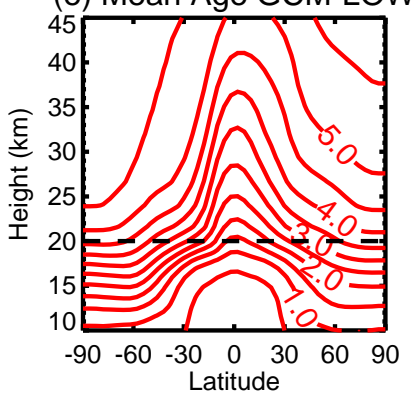

(c) Cly DAS-LOW
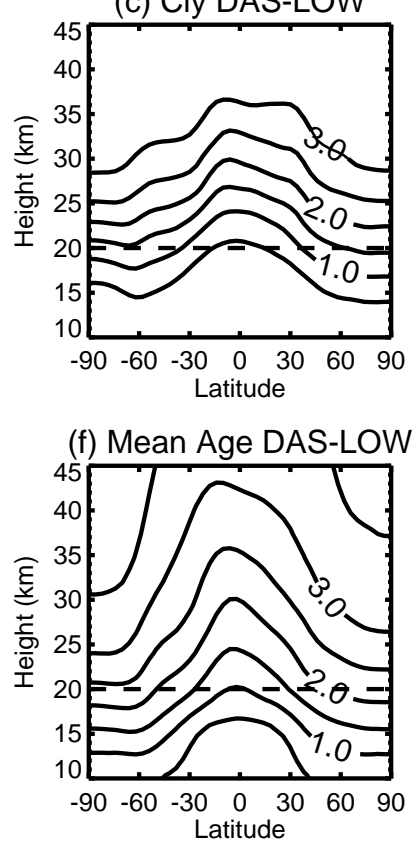

Fig. 1. Contour plots of (a-c; top panels) October-mean $\mathrm{Cl}_{\mathbf{y}}$, and (d-f; lower panels) annual-mean mean age for 2000, from three CTM simulations. In $(\mathrm{a}-\mathrm{c})$ the contour interval is $0.5 \mathrm{ppb}$, while in $(\mathrm{d}-\mathrm{e})$ the contour interval is 0.5 years.

\section{Model description}

The simulations examined are performed using the NASA Global Modeling Initiative (GMI) CTM (Douglass et al. (2004) and references therein). The CTM includes a full description of stratospheric chemistry, and can be driven by meteorological data from either a free-running general circulation model (GCM) or from a data assimilation system (DAS). We consider both cases here: Simulations are analyzed that used either the Goddard Earth Observing System (GEOS) DAS (Schubert et al., 1993) or the GEOS-4 GCM (Bloom et al., 2005).

We consider three different simulations with one pair differing in meteorological fields driving the CTM, and one pair differing in horizontal resolution and model top. Specificially, we consider simulations:

1. GCM winds, $2^{\circ}$ latitude $\times 2.5^{\circ}$ longitude, top at $0.015 \mathrm{hPa}$ with 33 levels (“GCM-HIGH”).

2. GCM winds, $4^{\circ}$ latitude $\times 5^{\circ}$ longitude, top at $0.4 \mathrm{hPa}$ with 28 levels ("GCM-LOW").

3. DAS winds, $4^{\circ}$ latitude $\times 5^{\circ}$ longitude, top at $0.4 \mathrm{hPa}$ with 28 levels ("DAS-LOW").

The two "LOW" simulations are described in Considine et al. (2004), while the GCM-HIGH simulation is described in Douglass et al. (2006).
In each case a single year of meteorological fields is used in the CTM: For the DAS simulation the fields from 1 July 1999 to 30 June 2000 are used, while for GCM simulations the fields are from a year with a cold Arctic vortex (see Considine et al., 2004). The GCM simulation used climatological sea-surface temperatures, volcanic aerosols and solar variations were not included, and there was no QBO. All three simulations use the same chemical solver (see Douglass et al., 2004) and the concentration of halogens in the lower troposphere are specified as in table 4B-2 of WMO (2003). The source gas boundary conditions vary between years. In the GCM-HIGH simulation the boundary conditions start in 1974 and end in 2025. The "LOW" simulations were spun up for 5 years at 1995 source gas boundary conditions and then integrated through the year 2030. Because 1995 boundary conditions were used rather than 1990 to 1994 conditions in the spin up of the "LOW" simulations the stratospheric chlorine is over-estimated in the early part of these simulations. However, the difference is much smaller than the inter-model differences discussed below. For all simulation, fields have been archived every 5 years.

In addition to the above, simulations of an age spectrum tracer were performed for each CTM. In these simulations the mixing ratio of a conserved tracer in the lowest two model levels was set to 1 for the first month and then set to 0 for the rest of the 20 year runs. This tracer allows calculation of the mean age of air in the stratosphere as well as the full age spectrum (Waugh and Hall, 2002). 


\section{Simulations of $\mathrm{Cl}_{\mathrm{y}}$ and mean age}

We first consider the $\mathrm{Cl}_{\mathrm{y}}$ distribution in the three simulations. As shown in Fig. 1 (a-c; top panels) the general features of the $\mathrm{Cl}_{\mathrm{y}}$ distributions are the same, e.g., there are values larger than $3 \mathrm{ppb}$ in the upper stratosphere and lower values in the tropics than in mid- and high latitudes. However, there are quantitative differences, especially in the wintertime (southern) polar regions. For example, the South Pole $\mathrm{Cl}_{\mathrm{y}}$ at $20 \mathrm{~km}$ varies from less than $1.5 \mathrm{ppb}$ to around $3 \mathrm{ppb}$. As the surface concentrations of organic chlorine species and the chemistry are the same in all three simulations, this confirms the CCM results (Eyring et al., 2006) that transport plays a key role in determining $\mathrm{Cl}_{\mathrm{y}}$.

As $\mathrm{Cl}_{\mathrm{y}}$ is formed by conversion of organic chlorine into inorganic chlorine species within the stratosphere, the time spent in the stratosphere is expected to play an important role in determining $\mathrm{Cl}_{\mathrm{y}}$. We therefore next consider the distributions of the mean age $\Gamma$. As described above, $\Gamma$ is calculated from simulations of the age spectra, and represents the annual-mean $\Gamma$, see Waugh and Hall (2002). As shown in Fig. 1 (d-f; bottom panels) the mean age differs among all three simulations. The largest differences are between DASLOW and the two GCM simulations, with much younger ages in DAS-LOW. The younger ages in the DAS simulation are related to the excessive mixing in simulations using assimilated winds (e.g., Schoeberl et al., 2003). There are also differences in age between GCM-LOW and GCM-HIGH, but these are small in the lower stratosphere (e.g., the South Pole mean age at $20 \mathrm{~km}$ is $\approx 4.7 \mathrm{yrs}$ in both GCM simulations).

Comparison of the $\mathrm{Cl}_{\mathrm{y}}$ and $\Gamma$ distributions shows that $\mathrm{Cl}_{\mathrm{y}}$ is, in general, larger for older $\Gamma$. However, this comparison also suggests that differences in $\Gamma$ do not explain all the differences in $\mathrm{Cl}_{\mathrm{y}}$. This is clearly seen in vertical profiles within the spring Antarctic vortex. At $20 \mathrm{~km}$ the mean ages from the two GCM based simulations are very similar but there is a large difference in $\mathrm{Cl}_{\mathrm{y}}$, see Fig. 2a, b. Conversely, above this altitude there are much larger differences in mean age than in $\mathrm{Cl}_{\mathrm{y}}$ between these two simulations. Hence, there is not a simple relationship between differences in mean age and those in $\mathrm{Cl}_{\mathrm{y}}$.

To explore the differences in $\mathrm{Cl}_{\mathrm{y}}$ in more detail we compare the time series of lower stratospheric $\mathrm{Cl}_{\mathrm{y}}$ at two locations where $\Gamma$ is similar in the two GCM based simulations (Fig. 3). In mid-latitudes the two GCM simulations have very similar $\mathrm{Cl}_{\mathrm{y}}$ (Fig. 3a), but at the polar location there is a large difference (Fig. 3b). At both locations $\Gamma$ and $\mathrm{Cl}_{\mathrm{y}}$ from the DAS simulation are smaller than from the GCM simulations. Note, as discussed above, the two "LOW" simulations overestimate $\mathrm{Cl}_{\mathrm{y}}$ in 1995 because of the initial conditions used, and this results in higher $\mathrm{Cl}_{\mathrm{y}}$ in 1995 than in 2000 in these simulations.

The differences in $\mathrm{Cl}_{\mathrm{y}}$ could be due to differences in the simulated total amount of chlorine $\mathrm{Cl}_{\text {tot }}$ (the sum of organic and inorganic chlorine) in the stratosphere. However, $\mathrm{Cl}_{\text {tot }}$ (a)

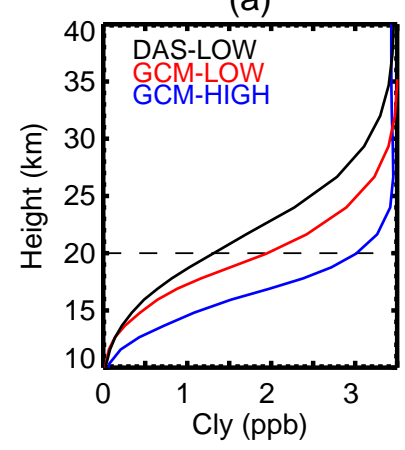

(c)

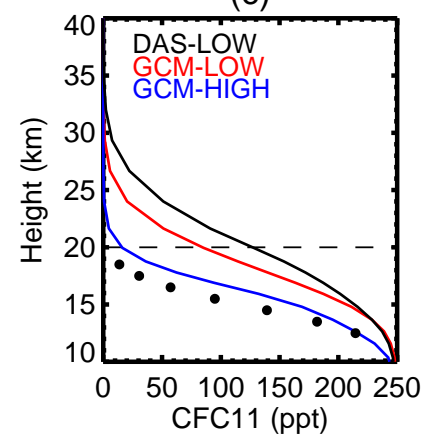

(b)

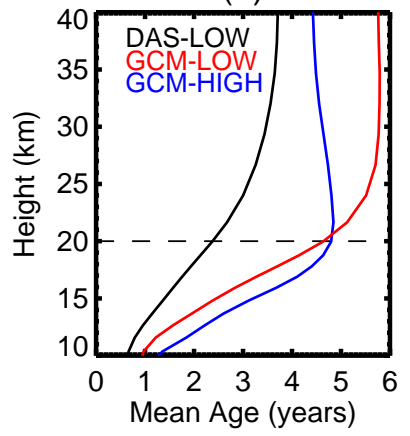

(d)

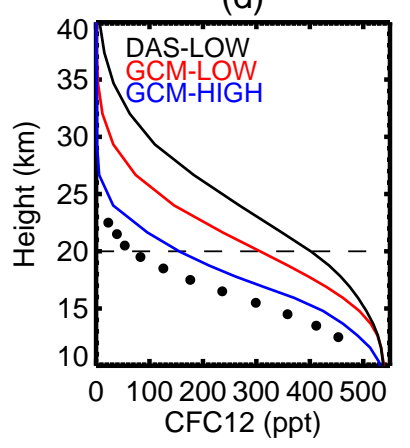

Fig. 2. Vertical profiles of (a) $\mathrm{Cl}_{\mathrm{y}}$, (b) mean age, (c) CFC-11, and (d) $\mathrm{CFC}-12$ at $82^{\circ} \mathrm{S}$. Profiles for $\mathrm{Cl}_{\mathrm{y}}$ are mean values for October 2000, mean age are annual mean values, and CFCs are for September 2005. The solid circles show ACE observations.

is very similar among all three simulations (dashed curves in Fig. 3). There is a slight time shift between the DAS and two GCM simulations, which is consistent with the approximately 2 year difference in the mean age. However, the magnitude of $\mathrm{Cl}_{\text {tot }}$ is very similar and differences in $\mathrm{Cl}_{\text {tot }}$ do not explain the differences in $\mathrm{Cl}_{\mathrm{y}}$. As well as the time shift in $\mathrm{Cl}_{\text {tot }}$ between the DAS and GCM simulations there are slight differences in the peak values, which are due to differences in the width of the age spectra. However these differences are insignificant compared to the differences in $\mathrm{Cl}_{\mathrm{y}}$.

The above shows that the time spent in the stratosphere is important but this is not the sole transport factor determining stratospheric $\mathrm{Cl}_{\mathrm{y}}$ (and differences between the simulations). Hence, the paths taken to get to a particular location must also be important for determining $\mathrm{Cl}_{\mathrm{y}}$.

\section{Fractional release rates}

To understand the differences in simulated $\mathrm{Cl}_{\mathrm{y}}$ we estimate the $\mathrm{Cl}_{\mathrm{y}}$ using the formulation of Newman et al. (2006, 2007). In this formulation $\mathrm{Cl}_{\mathrm{y}}$ is estimated by summing the contribution from each $\mathrm{CFC}$, i.e.,

$\mathrm{Cl}_{\mathrm{y}}^{*}(t)=\sum_{i} n_{i} F_{i} \hat{\rho}_{i}(t)$ 
(a)

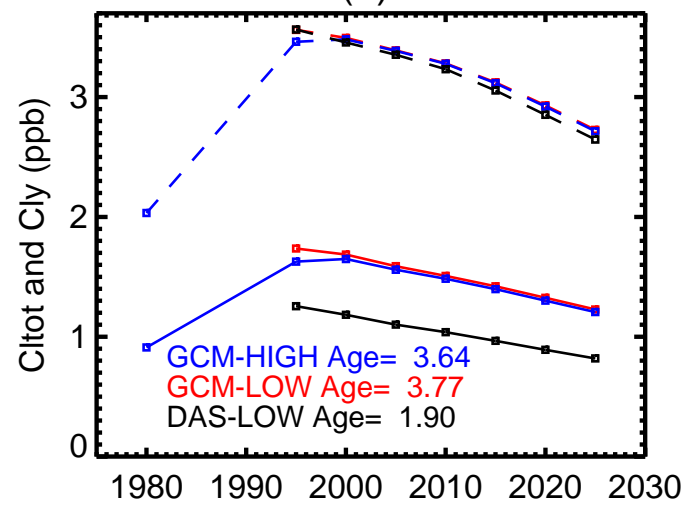

(b)

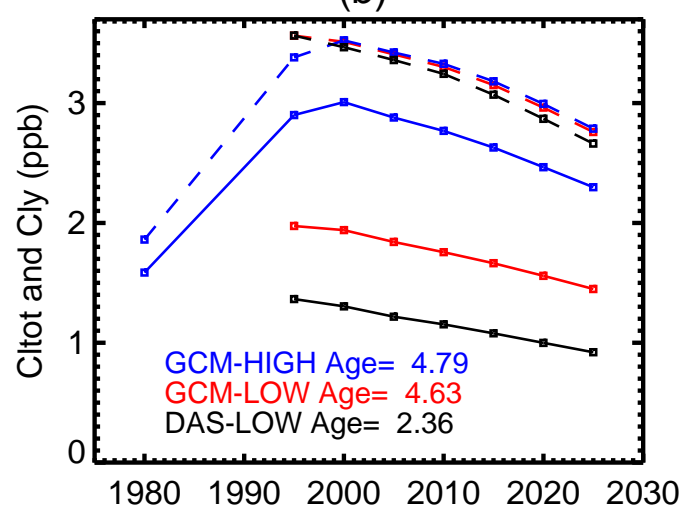

Fig. 3. Time series of October-mean $\mathrm{Cl}_{\mathrm{y}}$ (solid) and $\mathrm{Cl}_{\text {tot }}$ (dashed) at $56.6 \mathrm{hPa}$ for (a) mid-latitude $\left(46^{\circ} \mathrm{S}\right)$ and (b) polar $\left(82^{\circ} \mathrm{S}\right)$ regions.

where $n_{i}$ is the number of chlorine atoms in source gas $i, \hat{\rho}_{i}$ is the mixing ratio in the stratosphere that would occur if the source gas $i$ was perfectly conserved, and $F_{i}$ is the fraction of species dissociated while it has been in the stratosphere. The mixing ratio $\hat{\rho}_{i}$ depends on the tropospheric concentrations $\left(\rho_{i}\right.$,trop $)$ and the troposphere to stratosphere transport time scales:

$\hat{\rho}_{i}(t)=\int_{-\infty}^{t} \rho_{i, \text { trop }}\left(t^{\prime}\right) G\left(t-t^{\prime}\right) d t^{\prime}$

where $G(t)$ is the age spectrum. The fractional release is given by

$F_{i}=\left(\hat{\rho}_{i}-\rho_{i}\right) / \hat{\rho}_{i}$,

where $\rho_{i}$ is the actual concentration of the source gas at given stratospheric location.

We focus here on lower stratospheric $\mathrm{Cl}_{\mathrm{y}}$ and, as in Newman et al. (2006), assume that the fractional releases are solely a function of the mean age, i.e. $F_{i}=F_{i}(\Gamma)$. Although

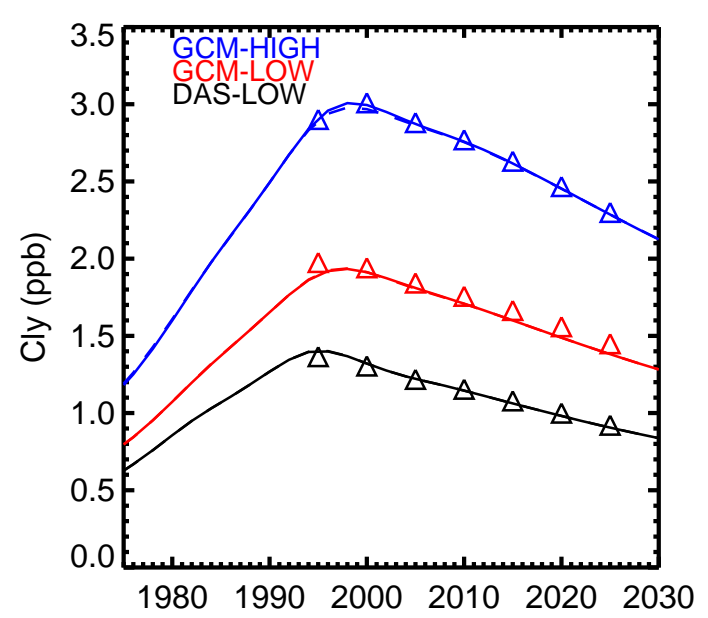

Fig. 4. Comparison of directly simulated $\mathrm{Cl}_{\mathrm{y}}$ at $56.6 \mathrm{hPa}$ and $82^{\circ} \mathrm{S}$ (symbols) and reconstruction using Newman et al. method (curves), for the three simulations. The solid curves show estimates using simulated age spectra, whereas the dashed curves, which generally cannot be distinguished from the solid curves, show estimates using inverse Gaussian age spectra.

we assume a dependence only on the mean age it is important to know that the release rates also depend on pathways, and the functional relationships are not necessarily the same for all simulations. $F_{i}(\Gamma)$ are determined separately for the three simulations using Eqs. (2) and (3).

We first compare $\mathrm{Cl}_{\mathrm{y}}^{*}$ calculated using (1) with the directly simulated $\mathrm{Cl}_{\mathrm{y}}$. In these calculations of $\mathrm{Cl}_{\mathrm{y}}^{*}$ we use the age spectrum $\mathrm{G}(\mathrm{t})$ simulated within the CTMs (see Sect. 2), the $\rho_{i}$,trop used in the CTMs, and the above estimates of $F_{i}$ calculated from model fields. As shown in Fig. 4 the $\mathrm{Cl}_{\mathrm{y}}^{*}$ estimated from $\mathrm{G}(\mathrm{t})$ and $F$ matches the time evolution of $\mathrm{Cl}_{\mathrm{y}}$ and the differences between the simulations. There are some differences between $\mathrm{Cl}_{\mathrm{y}}^{*}$ and $\mathrm{Cl}_{\mathrm{y}}$ for GCM-LOW, but these differences are much smaller than model-model differences, and $\mathrm{Cl}_{\mathrm{y}}^{*}$ is a good representation of $\mathrm{Cl}_{\mathrm{y}}$ to within a few percent. Note that virtually the same $\mathrm{Cl}_{\mathrm{y}}^{*}$ is obtained if the approximate age spectrum used by Newman et al. (2006) (an inverse Gaussian age spectrum with width equal to half the mean age) is used rather than the true model age spectrum. The dashed curves in Fig. 4 show $\mathrm{Cl}_{\mathrm{y}}^{*}$ from these calculations, and a virtually indistinguishable from the solid curves.

The good agreement between $\mathrm{Cl}_{\mathrm{y}}^{*}$ and the directly simulated $\mathrm{Cl}_{\mathrm{y}}$ supports the use of the method of Newman et al. (2006) for calculating EESC. If $\Gamma$ and $F_{i}$ are known then the Newman et al. (2006) method can accurately predict EESC. Both $\Gamma$ and $F_{i}$ could change in the future, and this will add uncertainties to estimates of EESC (Newman et al., 2007).

Given this general agreement we can now explore the differences in the individual contributions to $\mathrm{Cl}_{\mathrm{y}}^{*}$. As $\rho_{i}$, trop is the same in all simulations and the differences in $\mathrm{Cl}_{\text {tot }}$ are 
(a)

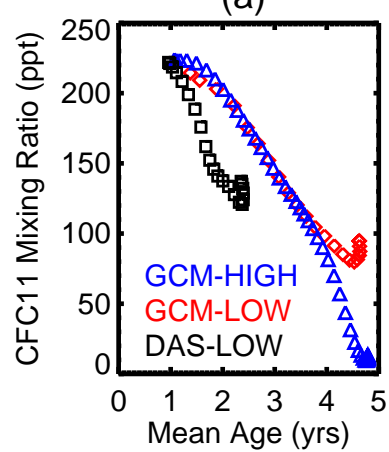

(c)

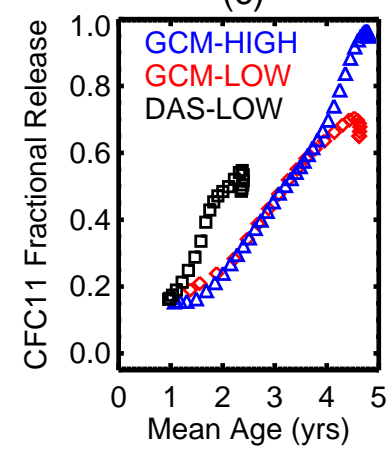

(b)

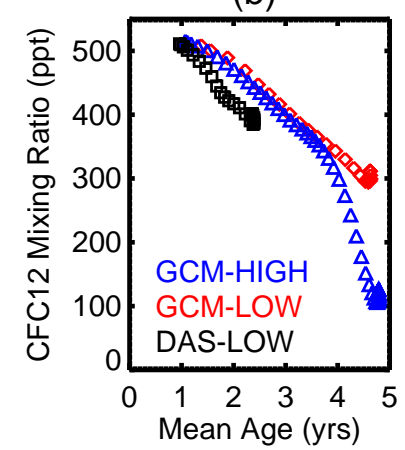

(d)

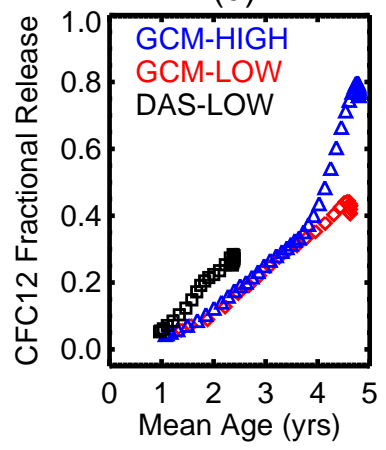

Fig. 5. Variation of (a) CFC-11 concentration, (b) CFC-12 concentration, (c) $F_{\mathrm{CFC} 11}$, and (d) $F_{\mathrm{CFC} 12}$ with mean age, $\Gamma$, for the three simulations.

small, differences in fractional release are the main cause for differences in $\mathrm{Cl}_{\mathrm{y}}$.

Figure 5 shows the variation of lower stratospheric concentration (a, b; top panels) and fractional release $F$ (c, d; bottom panels) with mean age $\Gamma$, for CFC-11 (left) and CFC12 (right). Very similar results are found for other CFCs. Focusing first on the two GCM based simulations we see that the CFC concentrations and $F$ are very similar for $\Gamma<4$ years, but differences occur for older ages. For old ages (polar air) the CFC concentrations are lower for GCM-HIGH, which means that the fraction of CFC converted into $\mathrm{Cl}_{\mathrm{y}}$ is larger (i.e. $F$ is larger). Thus, differences in transport can result in differences in the fraction of organic chlorine converted into $\mathrm{Cl}_{\mathrm{y}}$, and hence differences in $\mathrm{Cl}_{\mathrm{y}}$, for air with the same mean age.

The fractional release rates for the DAS simulation differs from both the GCM simulations. The maximum values of both $\Gamma$ and $F$ are smaller in the DAS simulation (the smaller $F$ is consistent with the smaller lower stratospheric $\mathrm{Cl}_{\mathrm{y}}$ in the DAS simulation). For given $\Gamma, F$ is larger from the DAS simulation than the GCM simulations. In the lower stratosphere, a given mean age will be found at higher latitude in the DAS simulation compared with the GCM simulations, e.g., air at $20 \mathrm{~km}$ with $\Gamma=2.4 \mathrm{yrs}$ in the DAS simulation is

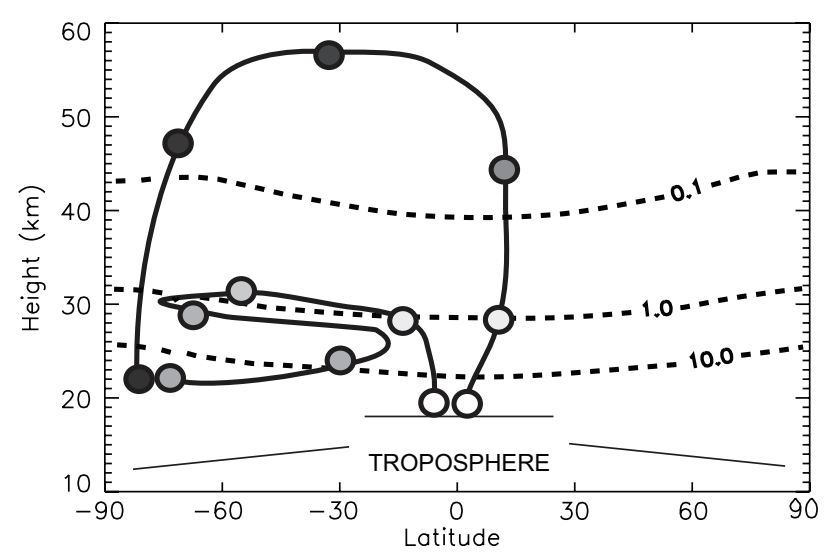

Fig. 6. Schematic diagram showing path of two irreducible parcels to sample point in polar lower stratosphere. The circles show the parcels locations at yearly intervals, with shading of the parcels indicating the $\mathrm{Cl}_{\mathrm{y}}$ of the parcel (darker color represents a higher amount). The dashed contours show local photochemical lifetime of CFC-12, in years.

at the South Pole, whereas $\Gamma=2.4 \mathrm{yrs}$ is in the subtropics in both GCM simulations (Fig. 1). A higher latitude location generally has a higher percentage of air that has been in CFC loss regions, and so higher latitude air with the same age will have higher $F$. If comparisons between $F$ are made at the same location then $F$ is smaller in the DAS simulation than the GCM simulations, and as a result $\mathrm{Cl}_{\mathrm{y}}$ is smaller.

The differences in the fractional release of CFCs in the Antarctic vortex can be clearly seen in the vertical profiles of the CFCs, see Fig. 2c, d. One consequence of this is that observations of CFCs can probably be used to differentiate model simulations of $\mathrm{Cl}_{\mathrm{y}}$. For example, the solid circles in Fig. 2c, d show the monthly average CFCs near $80^{\circ} \mathrm{S}$ from the Atmospheric Chemistry Experiment (ACE) (Bernath et al., 2005) observations in September 2005. (The model and ACE CFCs are from September rather than October as ACE samples south of $79^{\circ} \mathrm{S}$ in early September but not later.) All three simulations overestimate the observed CFC abundances, with the best agreement for the GCM-HIGH simulation. This suggests that GCM-HIGH has the most realistic simulation of $\mathrm{Cl}_{\mathrm{y}}$.

Unfortunately, the corresponding profiles of $\mathrm{Cl}_{\mathrm{y}}$ cannot be determined directly from ACE as $\mathrm{Cl}_{2} \mathrm{O}_{2}$ (which is a significant reservoir of $\mathrm{Cl}_{\mathrm{y}}$ inside Antarctic lower stratospheric vortex in September) is not measured. However, measurements of $\mathrm{HCl}$ and $\mathrm{ClO}$ in October 2005 by Aura MLS indicate that at $20 \mathrm{~km} \mathrm{Cl}_{\mathrm{y}}$ is $\approx 3.3 \mathrm{ppb}$ (Fig. $4-8$ of WMO, 2007). Consistent with the above CFC comparisons, the modeled $\mathrm{Cl}_{\mathrm{y}}$ are too low, with GCM-HIGH the most realistic. 


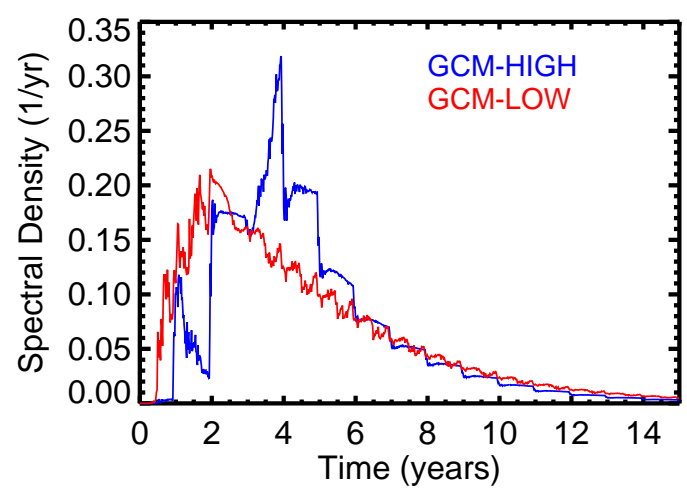

Fig. 7. Age spectrum at $56.6 \mathrm{hPa}$ and $82^{\circ} \mathrm{S}$ from GCM-HIGH (blue) and GCM-LOW (red) simulations.

\section{Transport pathways}

Previous analysis of models has shown that $\Gamma$ is very important for correctly estimating $\mathrm{Cl}_{\mathrm{y}}$. However, the above comparisons have shown that although the mean age in the polar lower stratosphere may be the same in two simulations, this does not mean that $\mathrm{Cl}_{\mathrm{y}}$ will be the same. It is important to consider the pathways that the air has taken, which can be different even if $\Gamma$ is the same. Even if two parcels have the same $\Gamma$ one parcel could have lower CFC concentrations, higher fractional releases, and larger $\mathrm{Cl}_{\mathrm{y}}$ if this parcel spent more time in regions with larger CFC photolysis. This is illustrated schematically in Fig. 6 which shows two parcels with same transit time from the tropopause but different pathways. As a result the two parcels have different photochemical exposure (Schoeberl et al., 2000) and $\mathrm{Cl}_{\mathrm{y}}$.

The larger CFC concentrations, and hence smaller $\mathrm{Cl}_{\mathrm{y}}$, in the GCM-LOW simulation could be explained by a smaller fraction of the polar air having been in the middle-upper stratosphere where CFCs are photolyzed. This is supported by the analysis of Strahan and Polansky (2006). They showed that with lower horizontal resolution there are leakier transport barriers (in subtropics and edges of polar vortices), which results in more rapid transport of young air to polar regions. The leakier barriers also allow more recirculation of air between the tropics and extratropics, allowing air to become old without spending time in the upper stratosphere. The greater influence of young air in the GCM-LOW simulation can also be seen in the age spectra, see Fig. 7 (see also Fig. 14 of Strahan and Polansky, 2006). In the GCM-LOW simulation there is a much higher percentage of young air ( $<2$ years) than in the GCM-HIGH simulation. Also, air arrives continuously in GCM-LOW whereas the GCM-HIGH simulation shows an episodic annual injection of air into the polar region in the transport (Strahan and Polansky, 2006).

\section{Conclusions}

The CTM simulations presented here show that transport plays a key role in determining the distribution of $\mathrm{Cl}_{\mathrm{y}}$, and that large differences in $\mathrm{Cl}_{\mathrm{y}}$ can occur in models using the same surface concentrations of source gases and same chemistry. The time air spends in the stratosphere (e.g., the mean age, $\Gamma$ ) is an important factor but this is not the sole transport factor determining stratospheric $\mathrm{Cl}_{\mathrm{y}}$. Stratospheric $\mathrm{Cl}_{\mathrm{y}}$ also depends on where the air has been. Differences in transport pathways can result in differences in the fraction of air that has been in the upper stratosphere, where organic chlorine is converted into $\mathrm{Cl}_{\mathrm{y}}$, even for air with the same mean age. Thus there can be differences in $\mathrm{Cl}_{\mathrm{y}}$ for air with the same $\Gamma$.

This analysis shows that to correctly model $\mathrm{Cl}_{\mathrm{y}}$ it is necessary to correctly simulate both the time scales and pathways for stratospheric transport. The mean age provides a stringent test of the transport time scales, and can be inferred from observations. A complementary test of transport pathways is also required. Hall (2000) introduced the "maximum path height" distribution which quantifies transport pathways and complements the age spectrum. However, this quantity cannot be observed. We therefore have to rely on simulations of chemical species to assess the model transport. As shown above transport-induced differences in $\mathrm{Cl}_{\mathrm{y}}$ can be clearly seen in profiles of CFCs, and observations of CFCs (e.g., Fig. 2c, d) are available to assess the reality of the transport pathways in models. Hence, comparison of simulated mean age and CFCs with observations provide complementary tests that assess the transport time scales and pathways in models. The complementary nature of tracers with different lifetimes for evaluating transport can also be seen in Schoeberl et al. (2005), where multiple tracers are used to constrain the age spectrum.

Acknowledgements. This work and the GMI model integrations were supported by NASA MAP and ACMAP projects. The ACE Mission is funded primarily by the Canadian Space Agency.

Edited by: M. Dameris

\section{References}

Bernath, P. F., McElroy, C. T., Abrams, M. C. et al.: Atmospheric Chemistry Experiment (ACE) mission overview, Geophys. Res. Lett., 32, L15S01, doi:10.1029/2005GL022386, 2005.

Bloom, S. C., da Silva, A. M., Dee, D. P., et al.: The Goddard Earth Observation System Data Assimilation System, GEOS DAS Version 4.0.3: Documentation and Validation, NASA TM- 2005104606 V26, 2005.

Considine, D. E., Connell, P. S., Bergmann, D. J., Rotman, D. A, and Strahan, S. E.: Sensitivity of Global Modeling Initiative model predictions of Antarctic ozone recovery to input meteorological fields, J. Geophys. Res., 109, D15301, doi:10.1029/2003JD004487, 2004. 
Douglass, A. R., Stolarski, R. S., Strahan, S. E., and Connell, P.S.: Radicals and reservoirs in the GMI chemistry and transport model: Comparison to measurements, J. Geophys. Res., 109, D16302, doi:10.1029/2003JD004632, 2004.

Douglass A. R., Stolarski, R. S., Strahan, S. E., and Polansky, B. C.: Sensitivity of Arctic ozone loss to polar stratospheric cloud volume and chlorine and bromine loading in a chemistry and transport model, Geophys. Res. Lett., 33, L17809, doi:10.1029/2006GL026492, 2006.

Eyring, V., Butchart, N., Waugh, D. W., et al.: Assessment of temperature, trace species, and ozone in chemistry-climate model simulations of the recent past, J. Geophys. Res., 111, D22308, doi:10.1029/2006JD007327, 2006.

Eyring, V., Waugh, D. W., Bodeker, G. E., et al.: Multi-model projections of stratospheric ozone in the 21 st century, J. Geophys. Res., 112, D16303, doi:10.1029/2006JD008332, 2007.

Hall, T. M.: Path histories and timescales in stratospheric transport: analysis of an idealized model, J. Geophys. Res., 105, $22811-$ $22823,2000$.

Newman, P. A., Nash, E. R., Kawa, S. R., Montzka, S. A., and Schauffler, S. M.: When will the Antarctic ozone hole recover?, Geophys. Res. Lett., 33, L12814, doi:10.1029/2005GL025232, 2006.

Newman, P. A., Daniel, J. S., Waugh, D. W., and Nash, E. R.: A new formulation of equivalent effective stratospheric chlorine, Atmos. Chem. Phys., 7, 4537-4552, 2007, http://www.atmos-chem-phys.net/7/4537/2007/.

Schauffler, S. M., Atlas, E. L., Donnelly, S. G., et al.: Chlorine budget and partitioning during the Stratospheric Aerosol and Gas Experiment (SAGE) III Ozone Loss and Validation Experiment (SOLVE), J. Geophys. Res.-Atmos., 108(D5), 4173, doi:10.1029/2001JD002040, 2003
Schoeberl, M. R., Sparling, L., Dessler, A., Jackman, C. H., and Fleming, E. L.: A Lagrangian view of stratospheric trace gas distributions, J. Geophys. Res., 10, 1537-1552, 2000.

Schoeberl, M. R., Douglass, A. R., Zhu, Z., and Pawson, S.: A comparison of the lower stratospheric age spectra derived from a general circulation model and two data assimilation systems, J. Geophys. Res., 108, 4113, doi:10.1029/2002JD002652, 2003.

Schoeberl, M. R., Douglass, A. R., Polansky, B., Boone, C., Walker, K. A., and Bernath, P.: Estimation of stratospheric age spectrum from chemical tracers, J. Geophys. Res., 110, D21303, doi:10.1029/2005JD006125, 2005.

Schubert, S., Rood, R., and Pfaendtner, J.: An assimilated dataset for earth sciences applications, B. Am. Meteorol. Soc., 74, 23312342, 1993.

Strahan S. E. and Polansky, B. C.: Meteorological implementation issues in chemistry and transport models, Atmos. Chem. Phys., 6, 2895-2910, 2006, http://www.atmos-chem-phys.net/6/2895/2006/.

Waugh, D. W. and Hall, T. M.: Age of stratospheric air: theory, observations, and models, Rev. Geophys., 40, 1010, doi:10.1029/2000RG000101, 2002.

World Meteorological Organization (WMO)/United Nations Environment Programme (UNEP), Scientific Assessment of Ozone Depletion: 2002, World Meteorological Organization, Global Ozone Research and Monitoring Project, Report No. 47, Geneva, Switzerland, 2003.

World Meteorological Organization (WMO)/United Nations Environment Programme (UNEP): Scientific Assessment of Ozone Depletion: 2006, World Meteorological Organization, Global Ozone Research and Monitoring Project, Report No. 50, Geneva, Switzerland, 2007. 